\section{Rationality and irrationality in the use of antibiotics in the epiclatino Latin American Neonatal Units}

\author{
Angela B Hoyos ${ }^{1,2 *}$ \\ ${ }^{1} \mathrm{MD}$, Head of Neonatology, Clínica del Country, Bogota, DC, Colombia \\ ${ }^{2}$ Professor of Pediatrics, Universidad El Bosque, Bogota DC, Colombia
}

\section{Abstract}

Background: Recent years have seen chaos in the neonatology use of antibiotics with diverse opinions and recommendations in international guidelines and societies. This has created great uncertainty in which cases to use, for how long, and which tests apply to make these decisions.

We conducted a retrospective cohort study about the use of antibiotics in the EpicLatino neonatal units and a Latin American network database, after noting these variations in the 2019 report.

Methods: For the year 2019 using the EpicLatino database, we included cases (only first admission) $\leq 32$ weeks gestational age at birth, excluding one unit that did not accept to participate.

The number of cases and days receiving antibiotics were recorded as well as the progression for each unit. Inappropriate use of antibiotics was defined as greater than 3 days in patients with negative cultures (blood/CSF cultures) excluding: major malformations, urinary tract infections, necrotizing enterocolitis (NEC) and cases with suspected chorioamnionitis in the mother (the latter two only during the course of diagnosis of NEC or chorioamnionitis).

Results: A total of 6,543 days of antibiotics were observed, $49.5 \%$ of cases had at least one positive blood/CSF culture.

A total of 595 days of antibiotics without justification were found in 72 courses in 61 cases: $19.4 \%$ had no diagnosis of infection in the database, $9.7 \%$ did not document any culture throughout their stay, and $51,4 \%$ obtained only one blood/CSF culture during their entire stay. In the 58 cases with diagnosis of infection: $41 \%$ were clinical sepsis and a diagnosis of pneumonia with a poor positive culture correlation was found. Furthermore, $74 \%$ of the unit's didn't use pneumonia as a justification to use antibiotics.

Other diagnosis found: Conjunctivitis, NEC $1 \mathrm{~A}$ and rotavirus NEC

Conclusion: Although the method of reviewing the use of antibiotics in a database has a number of limitations, especially the cause that motivated the use of antibiotics and other tools used for diagnosis of infections, the notable differences between units is striking.

Although it is difficult to make recommendations to all units, it is important to control infections in some units and in others to reduce the excessive use of antibiotics, especially with diagnosis of pneumonia in neonates and negative blood/CSF cultures.

\section{More Information}

*Address for Correspondence:

Angela B Hoyos, Unidad de Neonatología,

Clínica del Country, Cra 15 \# 84-13, Bogotá DC, Colombia, Tel: +57 3157926533;

Email: angela.hoyos@clinicadelcountry.com; hoyosangela@yahoo.com

Submitted: March 10, 2021

Approved: March 26, 2021

Published: March 29, 2021

How to cite this article: Hoyos AB. Rationality and irrationality in the use of antibiotics in the epiclatino Latin American Neonatal Units. J Adv Pediatr Child Health. 2021; 4: 035-037.

DOI: 10.29328/journal.japch.1001028

Copyright: @ 2021 Hoyos AB. This is an open access article distributed under the Creative Commons Attribution License, which permits unrestricted use, distribution, and reproduction in any medium, provided the original work is properly cited.

Keywords: Antibiotic use; Neonatal Units; EpicLatino; Latin America

(W) Check for updates

OPEN ACCESS

\section{Introduction}

Recent years have seen chaos in the neonatology use of antibiotics, with diverse opinions and recommendations in international guidelines and societies [1-4], some of them published some time ago [5]. This has created great uncertainty in which cases apply, for how long, and which tests are needed to make these decisions. Unfortunately, studies with sufficient scientific rigor are scarce, the diagnostic elements are very imprecise and the opinions are not always based on scientific studies.

\section{Materials and methods}

EpicLatino is a prospective quality improvement database of neonatal intensive care units across Latin America based on the CNN (Canadian Neonatal Network) collection 
instrument. It includes 20 units from Argentina, Colombia, Curaçao, Ecuador, Mexico and Paraguay. All patients are followed from admission to discharge, some units include all their patients and others only cases $\leq 32$ weeks GA at birth.

Since 2015 the EpicLatino webpage has published a yearly report with all the relevant risk data and outcomes of these infants. The 2019 report is available in English [6]. All data from EpicLatino has been approved by every local ethic committee and data is anonymized for the patient's protections.

In the year 2019 using the EpicLatino database, we included cases (only first admission) $\leq 32$ weeks gestational age at birth, excluding one unit that did not accept to participate.

The inappropriate use of antibiotics was defined and quantified as a course of antibiotics of greater than 3 days in cases with negative cultures (blood/CSF) and the following conditions were excluded: major malformations, urinary tract infections, necrotizing enterocolitis (NEC) and cases with suspected chorioamnionitis in the mother (in the last two, only courses after birth and during the initial NEC course were excluded).

\section{Results}

With the basis described in the previous paragraph, 595 days of antibiotics without justification were found in 72 courses in 61 cases.

Of the 72 courses, $19.4 \%$ had no diagnosis of infection in the database, $9.7 \%$ did not show any documented blood or CSF culture throughout their stay, and $1.4 \%$ showed only one blood/CSF culture during their entire stay.

Of the 58 courses that did have a diagnosis of infection we found there was one case of conjunctivitis, one case of NEC stage $1 \mathrm{~A}$ and one case of NEC apparently due to rotavirus.

In the 58 cases diagnosed with infection, clinical sepsis was used, and in $41 \%$ the diagnosis of pneumonia was also included.

The use of prolonged courses in some patients with NEC (up to 42 days) is also noteworthy; however, these were not included in the previous count as by definition, because they were courses without interruption.

To make a graphic depiction, we compared the number of infections per 1000 days of stay for each center and the number of cases per 1000 days of stay for each center without justification in the use of antibiotics according to the criteria explained above (Figure 1).

In view of the large number of cases diagnosed with pneumonia with unjustified antibiotic use as described, the data of all these cases was reviewed for more than 3 day's course, by unit. From the selected courses, the percentage of positive cultures in blood or CSF was calculated by unit. It was found that 5 centers used this diagnosis as the reason to prescribe antibiotics and 1 unit used the diagnosis of pneumonia in 50/87 (57\%) of cases (Figure 2). Furthermore, only $14 \%$ of these pneumonia diagnosed cases had blood or CSF positive cultures in this particular unit. In the rest of the 19 Epic Latino units (74\%), this diagnosis was not used.
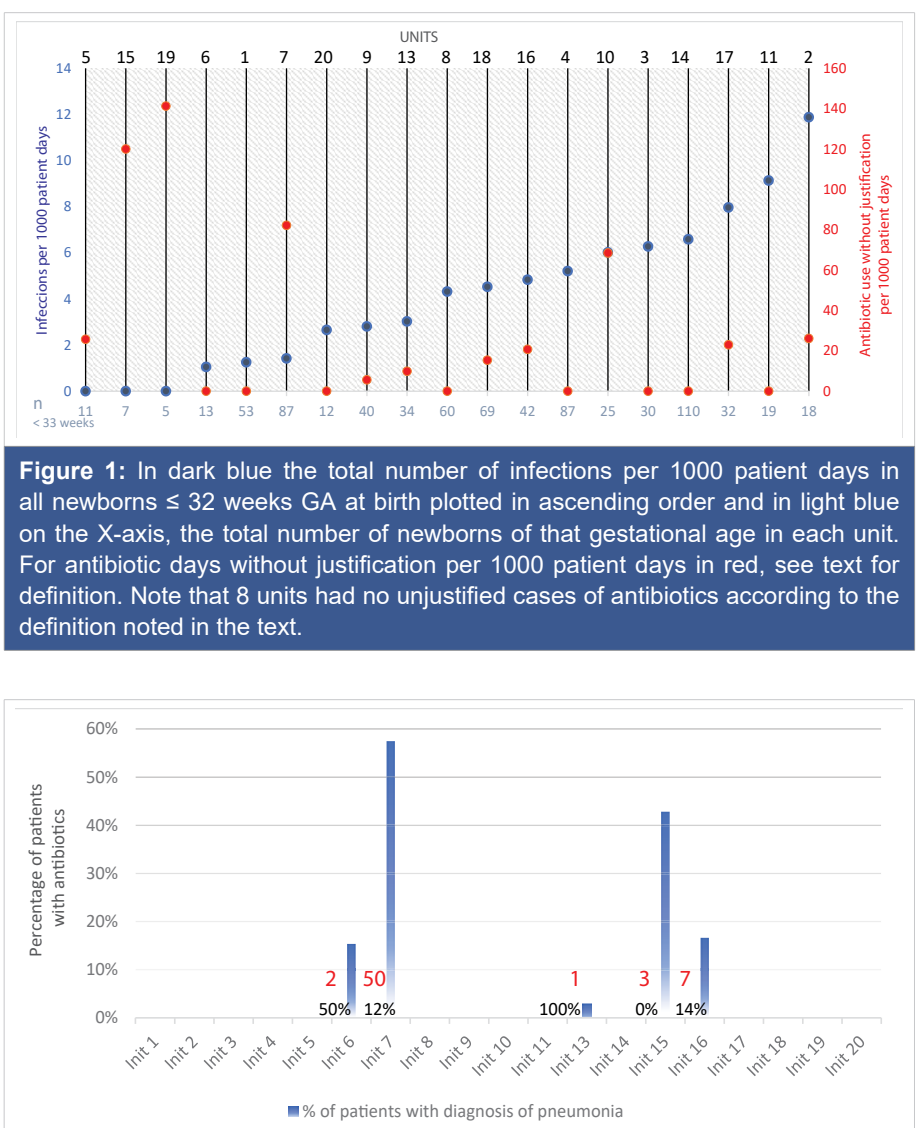

Figure 2: Only 5 units with a diagnosis of intra- or extra-uterine pneumonia as justification for the use of antibiotics (blue bars in percentage) of the total of patients $\leq 32$ weeks of GA at birth with antibiotics. In red the number of cases and in black below the percentage of positivity of blood/CSF cultures.

\section{Discussion and conclusion}

As seen in medical literature, the use of antibiotics does not follow any rationale in many of these units with wide differences in practically all the parameters reviewed. The most up to date parameters in neonates are not easy to define, but using Redbook 2018 [1], even if only for recommendations by an authorized group would be: not to start antibiotics if the suspected infection does not have a solid basis, stop antibiotics after 48 hours if cultures test negative, or after 7-14 days if the cultures were positive. Note that the cases of antibiotic use that could justify their use without positive cultures such as NEC or major malformations among others, were excluded from this work.

A limitation to the study was that it was not possible to consider the time taken to release microbiological tests, nor 
was it possible to establish if the diagnosis of pneumonia included assessments about sputum culture, chest X-ray, or trouble breathing, or which antibiotics were used in each case as well as other tools or information. Although the method of reviewing antibiotic use in a database has certain flaws, the extreme differences between units is striking. Units with few patients represent a large risk for error and the data collection rigor may not be the best in some cases, but there are several units in the study with a considerable number of cases that show very large differences.

The use of pneumonia as a diagnosis in neonates to prescribe antibiotics in 5 units and almost $60 \%$ of all newborns in one unit is striking, considering the low percentage of positive blood/CSF cultures, while in $74 \%$ of the remaining units the diagnosis of pneumonia doesn't even appear.

It is difficult to make recommendations regarding the use of antibiotics in neonates, given that the use of these medications is particularly important to control infections, but units should reduce the use of antibiotics relating to pneumonia diagnosed cases with negative blood/CSF cultures.

To use antibiotics for fear of an infection without a clear medical basis is irrational.

\section{Acknowledgement}

We want to thank EpicLatino, its board of directors and the participating units for letting us use their data and for systematically entering the information to have a reliable database and thus be able to do this type of work.

\section{Statement of ethics}

EpicLatino is a prospective quality improvement database of neonatal intensive care units across Latin America. All data from EpicLatino has been approved by every local ethic committee and data is anonymized for the patient's protections.

\section{Author contribution}

ABH designed, obtained data, made the statistical calculations, wrote and approved the final content.

\section{References}

1. Red Book 2018. Copyright. In: Kimberlin DW, Brady MT, Jackson MA, Long SS, eds. Red Book: 2018 Report of the Committee on Infectious Diseases. Am Acad Pediat. 2018. Pediatrics AAo. 2021.

2. Cook A, Hsia Y, Russell N, Sharland M, Cheung K, et al. Association of Empiric Antibiotic Regimen Discordance With 30-Day Mortality in Neonatal and Pediatric Bloodstream Infection-A Global Retrospective Cohort Study. Pediatr Infect Dis J. 2021; 40: 137-143.

PubMed: https://pubmed.ncbi.nlm.nih.gov/33395208/

3. Rosati P, Saulle R, Amato L, Mitrova Z, Crocoli A, et al. Mindful organizing as a healthcare strategy to decrease catheter-associated infections in neonatal and pediatric intensive care units. A systematic review and grading recommendations (GRADE) system. J Vasc Access. 2021: 1129729821990215.

PubMed: https://pubmed.ncbi.nlm.nih.gov/33570016/

4. McMullan BJ, Campbell AJ, Blyth CC, McNeil JC, Montgomery CP, et al. Clinical Management of Staphylococcus aureus Bacteremia in Neonates, Children, and Adolescents. Pediatrics. 2020;146: e20200134. PubMed: https://pubmed.ncbi.nlm.nih.gov/32759380/

5. Fuchsa A, Bielickia J, Mathurb S, Sharlandb M, Van Den Anker JN. Antibiotic Use for Sepsis in Neonates and Children: 2016, Evidence Update. WHO: WHO. 2016.

6. EpicLatino. Epiclatino Repport 2019. https://www.epiclatino.co/report-2019 